\title{
Deletion of the Transcription Factor PGC-1a in Mice Negatively Regulates Bone Mass
}

\author{
Graziana Colaianni $^{1} \cdot$ Luciana Lippo $^{1,8} \cdot$ Lorenzo Sanesi $^{1} \cdot$ Giacomina Brunetti $^{2} \cdot$ Monica Celi $^{3} \cdot$ Nunzio Cirulli $^{2}$. \\ Giovanni Passeri $^{4}$. Janne Reseland ${ }^{5}$. Ernestina Schipani ${ }^{6} \cdot$ Maria Felicia Faienza $^{7}$. Umberto Tarantino ${ }^{3}$. \\ Silvia Colucci ${ }^{2} \cdot$ Maria Grano $^{1}$
}

Received: 8 April 2018 / Accepted: 16 July 2018 / Published online: 9 August 2018

(c) Springer Science+Business Media, LLC, part of Springer Nature 2018

\begin{abstract}
Peroxisome proliferator-activated receptor-gamma coactivator $(\mathrm{PGC} 1 \alpha)$ is a transcription coactivator that interacts with a broad range of transcription factors involved in several biological responses. Here, we show that PGC1 $\alpha$ plays a role in skeletal homeostasis since aged PGC1 $\alpha$-deficient mice $\left(\mathrm{PGC} 1 \alpha^{-/-}\right)$display impaired bone structure. Micro-CT of the tibial mid-shaft showed a marked decrease of cortical thickness in PGC1 $\alpha^{-/-}(-11.9 \%, p<0.05)$ mice compared to wild-type littermate. Trabecular bone was also impaired in knock out mice which displayed lower trabecular thickness $(\mathrm{Tb}$.Th) $(-5.9 \%$ vs PGC1 $\left.\alpha^{+/+}, p<0.05\right)$, whereas trabecular number (Tb.N) was higher than wild-type mice $\left(+72 \%\right.$ vs PGC1 $\left.\alpha^{+/+}, p<0.05\right)$, thus resulting in increased $\left(+31.7 \%\right.$ vs PGC1 $\left.\alpha^{+/+}, p<0.05\right)$ degree of anisotropy (DA), despite unchanged bone volume fraction (BV/TV). Notably, these impairments of cortical and trabecular bone led to a dramatic $\sim 48.4 \%$ decrease in bending strength $(p<0.01)$. These changes in PGC1 $\alpha^{-/-}$mice were paralleled by a significant increase in osteoclast number at the cortical bone surface and in serum level of the bone resorption marker, namely, C-terminal cross-linked telopeptides of type I collagen (CTX-I). We also found that in cortical bone, there was lower expression of mRNA codifying for the key bonebuilding protein Osteocalcin $(O c n)$. Interestingly, Collagen I mRNA expression was reduced in mesenchymal stem cells from bone marrow of PGC1 $\alpha^{-/-}$, thus indicating that differentiation of osteoblast lineage is downregulated. Overall, results presented herein suggest that PGC1 $\alpha$ may play a key role in bone metabolism.
\end{abstract}

Keywords Peroxisome proliferator-activated receptor-gamma coactivator $\cdot$ Bone $\cdot$ Osteocalcin $\cdot$ Osteoclast $\cdot$ Osteoblast . Mitochondria

Graziana Colaianni, and Luciana Lippo have contributed equally to this work.

Electronic supplementary material The online version of this article (https://doi.org/10.1007/s00223-018-0459-4) contains supplementary material, which is available to authorized users.

Maria Grano

maria.grano@uniba.it

1 Department of Emergency and Organ Transplantation, University of Bari, Piazza Giulio Cesare 11, 70124 Bari, Italy

2 Department of Basic Medical Science, Neuroscience and Sense Organs, University of Bari, Bari, Italy

3 Department of Orthopedics and Traumatology, Tor Vergata University of Rome, Rome, Italy

4 Department of Clinical and Experimental Medicine, University of Parma, Parma, Italy

\section{Introduction}

Peroxisome proliferator-activated receptor- $\gamma$ coactivator $1-\alpha$ $(\mathrm{PGC} 1 \alpha)$ has emerged as a vital regulator of several cellular processes, as well as adaptive thermogenesis, glucose

5 Department of Biomaterials, Institute for Clinical Dentistry, University of Oslo, Oslo, Norway

6 Departments of Medicine and Orthopaedic Surgery, University of Michigan, Ann Arbor, MI, USA

7 Department of Biomedical Science and Human Oncology, Pediatric Unit, University of Bari, Bari, Italy

$8 \quad$ PhD School in Tissue and Organ Transplantation and Cellular Therapies, Department of Emergency and Organ Transplantation, School of Medicine-University of Bari, Bari, Italy 
metabolism, and skeletal muscle fiber-type specialization. Considered to be predominantly involved in the regulation of mitochondrial content and function [1-5], the expression of PGC1 $\alpha$ is greatly tuned in response to nutritional, hormonal, and environmental stimuli across a variety of tissues [6-8] to meet increased cellular energetic requirements. PGC $1 \alpha$ mRNA expression increases in brown fat following cold exposure, in skeletal muscle by bouts of physical activity $[3,9,10]$ and in the liver by short-term fasting [11]. Pups lacking PGC1 $\alpha$ were born at the expected Mendelian ratio, suggesting that $\mathrm{PGC} 1 \alpha$ is dispensable for embryonic development; however, approximately $50 \%$ of homozygotes exhibit postnatal lethality [12]. Mice homozygous for this targeted mutation are fertile and do not display any abnormalities in several tissues, such as heart, skeletal muscle, pancreas, and liver. However, knockout mice display abundant accumulation of large lipid droplets in the brown fat and are unable to survive after exposure to $4{ }^{\circ} \mathrm{C}$ for more than $6 \mathrm{~h}$. Studies on mice with whole-body deletion of PGC1 $\alpha$ reveal that null mice are surprisingly lean and insulin sensitive when fed on a high fat diet [12]. This observation suggests the existence of a PGC $1 \alpha$-mediated feedback pathway from muscle to the pancreas, but the identity of this pathway remains uncertain. Current evidences indicate that PGC $1 \alpha$ is a parathyroid hormone (PTH)-induced, cAMPdependent primary response gene that directly synergizes with the NR4A/NGFI-B orphan nuclear receptor (Nurr1) to transactivate target genes in osteoblasts [13]. Beyond a broadly documented role of PGC1 $\alpha$ in high energy-demand tissues, the effect of PGC1 $\alpha$ absence on bone has not yet been described. We show here that PGC1 $\alpha$-deficient mice display impaired bone structure, revealing that the absence of one of the master regulators of mitochondrial biogenesis can influence the microstructural and mechanical properties of bone. The defect appears evident in aged mice, whereas 3-months-old PGC1 $\alpha^{-/-}$mice display a bone phenotype comparable to wild type littermates, with only few exceptions in trabecular bone. Elucidation of the role of PGC1 $\alpha$ in bone remodeling could reveal novel insights into skeletal homeostasis for future development of drug targets and thus the prevention or treatment of skeletal involution.

\section{Methods}

\section{Experimental Design and Animal Model}

PGC1 $\alpha$ knockout, heterozygous and wild-type mice of mixed C57BL6/J-BALB/cOlaHsd background were generated as previously described [14]. 12-months-old male and female mice (total $n=26$ ) representative of the three genotypes (male mice $=5$ wild type, 5 heterozygous, 5 knockout; female mice $=4$ wild type, 4 heterozygous, 3 knockout) and
3 -months-old male and female mice (total $n=13$ ) representative of the two genotypes (male mice $=4$ wild type, 3 knockout; female mice $=3$ wild type, 3 knockout) were housed in standard rodent cages, maintained under standard conditions on a 12/12-h light/dark cycle and with access to water and regular chow diet ad libitum (Harlan Teklad 2019, SDS, England). Mice were weighed after being euthanized and their tissues were surgically excised. Spines, right femurs, and tibiae were harvested and stored in $70 \%$ ethanol to be employed for $\mu \mathrm{CT}$ and histological analysis. Left femurs and tibia were subjected to trabecular bone removal by passing a needle to open the medullary canal and allow the bone marrow flushing. Both bone marrow and bone were then stored in liquid nitrogen for quantitative PCR analysis. The femurs and the tibia were cut transversally, and the two halves were mixed and used for quantitative PCR analysis.

\section{Microcomputed Tomography Analysis of Femur}

MicroCT $(\mu \mathrm{CT})$ scanning was performed to measure morphological indices of metaphyseal regions of femurs. Femurs were rotated around their long axes and images were acquired using Bruker Skyscan 1172 (Kontich, Belgium) with the following parameters: pixel size $=5 \mu \mathrm{m}$; peak tube potential $=59 \mathrm{kV} ; \mathrm{X}$-ray intensity $=167 \mu \mathrm{A} ; 0.4^{\circ}$ rotation step. Raw images were reconstructed by the SkyScan reconstruction software (NRecon) to 3-dimensional cross-sectional image data sets using a 3-dimensional cone beam algorithm. Structural indices were calculated on reconstructed images using the Skyscan CT Analyzer (CTAn) software (Bruker). A set of three hydroxyapatite (HA) phantoms were scanned and used for calibration and to compute volumetric BMD. Cortical and trabecular bone were separated using a custom processing algorithm in CTAn, based on the different thicknesses of the structures. Cortical bone was assessed at the femoral midshaft. The scan volume of the femoral midshaft is centered on the midpoint of the bone, determined as half the distance from the distal condyle to the proximal point of the femoral head for all mice. Cortical bone was analyzed by a region of 150 slices, starting $9 \mathrm{~mm}$ distal to the metaphysis. Cortical parameters included cortical thickness (Ct.Th) and polar moment of inertia (pMOI). Trabecular bone was analyzed in the proximal metaphysis region, starting proximal to the distal growth plate and continuing distally for 200 slices. Trabecular parameters included bone mineral density (BMD), bone volume fraction (BV/TV), number (Tb.N), thickness (Tb.Th), and degree of anisotropy (DA). 


\section{Microcomputed Tomography Analysis of Tibiae}

Tibiae were rotated around their long axes and images were acquired using Bruker Skyscan 1172 (Kontich, Belgium) with the following parameters: pixel size $=5 \mu \mathrm{m}$; peak tube potential $=59 \mathrm{kV} ;$ X-ray intensity $=167 \mu \mathrm{A} ; 0.4^{\circ}$ rotation step. A set of three hydroxyapatite (HA) phantoms were scanned and used for calibration to compute volumetric BMD. For cortical bone properties, tibiae were scanned at the mid-diaphysis starting $5.5 \mathrm{~mm}$ from proximal tibial condyles and extending for $2006-\mu \mathrm{m}$ slices $(1.2 \mathrm{~mm})$. For trabecular bone, tibiae were scanned starting $1.9 \mathrm{~mm}$ from the proximal tibial condyles, just distal to the growth plate, in the direction of the metaphysis, and extending for 200 slices $(1.2 \mathrm{~mm})$.

\section{Microcomputed Tomography Analysis of Spine}

The fifth lumbar (L5) vertebrae of the spine were rotated around their long axes and images were acquired using Bruker Skyscan 1172 (Kontich, Belgium) with the following parameters: pixel size $=5 \mu \mathrm{m}$; peak tube potential $=59 \mathrm{kV} ; \mathrm{X}$-ray intensity $=167 \mu \mathrm{A} ; 0.4^{\circ}$ rotation step. The trabecular region of the vertebral body (excluding posterior elements) was designated using manually drawn contours inside the cortical shell surrounding the entire vertebral body enclosed by the growth plates and extending for $4506-\mu \mathrm{m}$ slices $(2.7 \mathrm{~mm})$.

\section{3-Point Bending Test of Mouse Femurs and Tibiae}

The tests were run on a Zwick tensile test machine (Zwick Roell, Ulm, Germany) with a $200 \mathrm{~N}$ load cell and the following test parameters: distance of lower supports: $12 \mathrm{~mm}$; pre-load: $0.1 \mathrm{~N}$; speed until pre-load: $20 \mathrm{~mm} / \mathrm{min}$; test speed: $10 \mathrm{~mm} / \mathrm{min}$.

The bones were stored in $70 \%$ ethanol at $4{ }^{\circ} \mathrm{C}$ before testing and taken out to be rehydrated and stored at room temperature in good time before the mechanical test (>30 min).

Length and diameter at mid shaft in the direction of the break force were measured for all the samples before testing. The samples were placed in a similar manner on the supports, with the distal end to the right and the proximal side to the left. The posterior surface was facing down. The bones were freed from any soft tissue and for the tibia the fibula removed on those samples where it was still attached.

\section{Histological Analysis of Bone and Adipose Tissues}

For dynamic bone-formation indices, mice were injected with calcein $(10 \mathrm{mg} / \mathrm{kg}$ body weight $)$ and xylenol orange (90 mg/kg body weight), 20 and 8 days before sample collection, respectively. Freshly dissected tibiae were immediately fixed in ice-cold $4 \%$ paraformaldehyde solution for $4 \mathrm{~h}$. After decalcification, performed with $0.5 \mathrm{M}$ ethylenediaminetetraacetic acid (EDTA) at $4{ }^{\circ} \mathrm{C}$, bones were immersed into $20 \%$ sucrose and $2 \%$ polyvinylpyrrolidone (PVP) solution for $24 \mathrm{~h}$. Tibiae were then embedded and frozen in optimal cutting temperature (OCT) compound (VWR Chemicals). For histological analyses, sections were generated by using a SLEE MEV Semi-Automatic Cryostat (SLEE medical $\mathrm{GmbH}$ ). To quantify the mineral apposition rate (MAR), bone formation rate (BFR), and mineralizing surface per bone surface (MS/BS), non-decalcified tibiae were immersed into $20 \%$ sucrose and 2\% PVP solution for $24 \mathrm{~h}$, then embedded in OCT and sections were generated by using a SLEE MEV Semi-Automatic Cryostat. Tartrate-resistant acidic phosphatase (TRAP) and Alkaline Phosphatase (ALP) positive cells were detected by using the Leukocyte Acid Phosphatase Kit and the Alkaline Phosphatase Kit (Sigma Aldrich), respectively. After TRAP staining, sections were counterstained with methyl green. For the analysis of bone marrow adipocytes, histological sections were washed with $60 \%$ isopropanol and let dry completely, then stained with freshly prepared oil red $\mathrm{O}$ working solution for $10 \mathrm{~min}$. After removal of oil red $\mathrm{O}$ solution, sections were rinsed in distilled water and tap water, then counterstained with hematoxylin for $10 \mathrm{~s}$ and mounted with a aqueous mounting medium. Histological sections were viewed under a Nikon Eclipse 80i light microscope (Nikon) using a $\times 40$ objective lens. Images were taken at $150 \mathrm{dpi}(3840 \times 3072$ pixels $)$ and analyzed by using Image-J software, by manually outlining bone surface. Three sections per sample and five high power fields for each section were analyzed.

Inguinal white adipose tissues were fixed overnight, then dehydrated, cleared, and embedded in paraffin. $5 \mu \mathrm{m}$ thick histological sections were cut and stained with hematoxylin and eosin (H\&E). All observations were performed with a Nikon Eclipse 80i light microscope (Nikon). The area of adipocytes was measured on pictures from $H \& E$ stained slides at $\times 40$ magnification by using the NIS-Element BR 4.10.00 software (Nikon, Japan).

\section{Enzyme-Linked Immunosorbent Assay (ELISA)}

Mice were fastened for $12 \mathrm{~h}$ before the sacrifice. Sera were collected at the time of sacrifice and assayed for circulating levels of procollagen type I-N-terminal propeptide (P1NP) and C-terminal telopeptide of type I-collagen (CTX-I) by ELISA kits (Immunodiagnostic Systems, Boldon, UK) 
following the manufacturer's protocol. Standard curves were generated using serial dilutions of the P1NP or CTX-I calibration standards supplied in the ELISA kit.

\section{Peroxidase Immunohistochemistry}

Immunohistochemistry was performed on $5 \mu \mathrm{m}$-thick OCT-embedded transverse sections of tibiae. Sections were reacted with $1 \% \mathrm{H}_{2} \mathrm{O}_{2}$ (in PBS; $30 \mathrm{~min}$ ) to block endogenous peroxidase, rinsed with PBS and incubated with $5 \mathrm{mg} / \mathrm{mL}$ Proteinase $\mathrm{K}$ solution at $37{ }^{\circ} \mathrm{C}$ for $5 \mathrm{~min}$. Then, sections were incubated with the mouse anti-Ocn primary antibody (Santa Cruz Biotechnology) overnight at $4{ }^{\circ} \mathrm{C}$. After a thorough rinse in PBS, sections were incubated with secondary antibody (MATCH 1 mouse probe, Biocare) at room temperature for $15 \mathrm{~min}$. Histochemical reaction was performed using HRP-polymer and DAB Chromogen (Biocare). Sections were counterstained with hematoxylin and mounted. Staining was never observed when the primary antibody was omitted. For morphometric analysis, immunostained bone sections were observed with a Nikon Eclipse 80i light microscope (Nikon) using a $\times 40$ objective. The percentage of Ocn protein stain was determined by the Nikon Lucia IMAGE (v. 4.61) image analysis software.

\section{Real Time-PCR}

Total RNA from mouse tissues was extracted using spin columns (RNeasy, Qiagen) according to the manufacturer's instructions. DNase I treatment was performed to remove genomic DNA contamination (Qiagen) and RNA integrity was assessed on agarose gels. Reverse transcription was performed using iScript Reverse Transcription Supermix (Bio$\mathrm{Rad}$ ). The resulting cDNA (20 ng) was subjected to quantitative PCR (qPCR) using the SsoFast EvaGreen Supermix (Bio-Rad) on an iCycler iQ5 Cromo4 (Bio-Rad) for 40 cycles (denaturation $95{ }^{\circ} \mathrm{C}$ for $5 \mathrm{~s}$; annealing/extension $60{ }^{\circ} \mathrm{C} 10 \mathrm{~s}$ ) after an initial $30 \mathrm{~s}$ step for enzyme activation at $95^{\circ} \mathrm{C}$. To confirm the specificity of amplification products, melting curve was performed between 65 and $96{ }^{\circ} \mathrm{C}$, with $0.5{ }^{\circ} \mathrm{C}$ incrementing every $10 \mathrm{~s}$. Primers were designed by using Primer Blast (https://www.ncbi.nlm.nih.gov/tools/ primer-blast/). Primer sequences are listed in Supplementary Table S2, where it is also indicated the accession number (NM_) and the product length for each primer. All primers span an exon-exon junction. Three housekeeping genes were chosen because they are normally stably expressed in bone and adipose tissues. Each transcript was assayed in triplicate and cDNA was normalized to murine Glyceraldehyde 3-phosphate dehydrogenase (GAPDH), $\beta 2$-microglobulin. and $\beta$-actin. Quantitative measures were obtained using the $\Delta \Delta \mathrm{CT}$ method.

\section{Cell Cultures}

Whole bone marrow cells were plated at a density of $4 \times 10^{5} \mathrm{cells} / \mathrm{cm}^{2}$ in 96 multiwell plates and cultured in $200 \mu \mathrm{L}$ per well of alphaMEM 10\% FBS in the presence of $5 \mathrm{ng} / \mathrm{mL}$ macrophage colony-stimulating factor (M-CSF) and $3 \mathrm{ng} / \mathrm{mL}$ RANKL. After $96 \mathrm{~h}$ of culture, cells were fixed with $10 \%$ formalin and stained for leukocyte acid phosphatase with TRAP kit (387A-1KT Sigma Aldrich). TRAPpositive multinucleated mature osteoclasts $(>3$ nuclei $<10$ and $>10$ nuclei) were then counted.

Bone marrow stromal cells were separated from monocytes through an overnight adhesion, then cultured in osteogenic medium with $\alpha$-MEM $/ 10 \%$ FBS, supplemented with $50 \mu \mathrm{g} / \mathrm{mL}$ ascorbic acid and $10^{-2} \mathrm{M} \beta$-glycerophosphate for 10 or 21 days. At the end of the culture period, ALP positive cells were detected by using ALP Kit (Sigma Aldrich) at day 10 and mineralized nodules were detected by using Von Kossa Staining at day 21. Bone marrow-derived macrophages were obtained from the non-adherent fraction of bone marrow cells and cultured with $\alpha$-MEM/10\% FBS, supplemented with $5 \mathrm{ng} / \mathrm{mL} \mathrm{M}-\mathrm{CSF}$, until confluence. Then, macrophages were detached by $0.25 \%$ Trypsin-EDTA solution, seeded at $100,000 / \mathrm{cm}^{2}$ and cultured in $\alpha$-MEM/10\% FBS, supplemented with $5 \mathrm{ng} / \mathrm{mL}$ M-CSF and $3 \mathrm{ng} / \mathrm{mL}$ RANKL for 7 days. At the end of the culture period, TRAPpositive multinucleated mature osteoclasts ( $>10$ nuclei) were detected by using TRAP Kit (Sigma Aldrich).

\section{Statistical Analysis}

One-way analysis of variance (ANOVA) was used for evaluating the existence of differences among the groups. When significant difference was detected, Bonferroni's post hoc analysis was used to determine the significance between every two groups. Values of $p<0.05$ were considered statistically significant.

\section{Results}

To determine whether PGC1 $\alpha$ deficiency leads to skeletal abnormalities, we examined long bones of PGC1 $\alpha$ wild type $\left(\mathrm{PGC} 1 \alpha^{+/+}\right)$, heterozygous $\left(\mathrm{PGC} 1 \alpha^{+/-}\right)$and knock out $\left(\mathrm{PGC} 1 \alpha^{-/-}\right)$mice. Bone defects were identical in male and female mice, therefore, data for both genders have been pooled.

To assess changes in bone structure, we performed microCT analysis on cortical and trabecular bone at midshaft and proximal tibia, respectively. Although no defects were observed in young mice (S1 Table), except for a significant reduction of BMD and Conn. Density in the trabecular bone of the tibia, PGC1 $\alpha^{-/-}$aged mice showed a defective bone 
phenotype, more prominent in the tibia. As showed by representative microCT-generated section images (Fig. 1a), measurement of cortical thickness (Ct.Th.) was lower in PGC1 $\alpha^{+/-}(-8.4 \%, p<0.05)$ and $\mathrm{PGC} 1 \alpha^{-/-}(-11.9 \%$, $p<0.05)$ mice compared to wild type littermate (Fig. 1a). In knockout mice, the length of the tibia was significantly lower, whereas the diameter was higher than wild type mice. However, this impairment of cortical structure was not accompanied by a change of polar moment of inertia (pMOI), an index of resistance to torsional forces. Interestingly, trabecular bone, although unaffected in heterozygous mice, was defective in knock out mice which displayed lower trabecular thickness (Tb.Th) $\left(-5.9 \%\right.$ vs PGC $1 \alpha^{+/+}$, $p<0.05)$, whereas trabecular number (Tb.N) was higher than wild type mice $\left(+72 \%\right.$ vs PGC $\left.1 \alpha^{+/+}, p<0.05\right)$, thus resulting in increased $\left(+31.7 \%\right.$ vs $\left.\mathrm{PGC} 1 \alpha^{+/+}, p<0.05\right)$ degree of anisotropy (DA), despite unchanged bone volume fraction (BV/TV) (Fig. 1b). Although there was no change of bone volume fraction, $\mathrm{PGC} 1 \alpha^{-l-}$ showed a significant increase of trabecular BMD, a defect opposite to that observed in the trabecular bone of 3-months-old knock out mice. Notably, these impairments of cortical and trabecular bone in PGC $1 \alpha$ knock out mice led to a dramatic $~ 48.4 \%$ decrease in bending strength $(p<0.01)$ compared with wild type and heterozygous mice (Fig. 1c). Moreover, also the energy to fracture, albeit not significantly, showed a tendency to decrease by $20 \%$ (Fig. 1d).

The bone defect was also evident in the femurs, although to a lesser extent compared to the tibia. By microCT analysis of femurs, we found that $\mathrm{Ct}$. Th. was lower in femurs from
Fig. 1 Effect of PGC1 $\alpha$ whole body deletion on cortical and trabecular bone of tibia. Representative micro-CT-generated section images of cortical (midshaft, a) and trabecular (metaphyseal, b) bone in tibia harvested from $\mathrm{PGC} 1 \alpha^{+/+}$, $\mathrm{PGC} 1 \alpha^{+/-}$and PGC $1 \alpha^{-/-}$mice. Cortical bone parameters included cortical thickness (Ct. Th), polar moment of inertia (pMOI), tibia length (t. length) and diameter (t. diameter). Trabecular bone parameters included bone volume/total volume (BV/TV), trabecular thickness ( $\mathrm{Tb} . \mathrm{Th}$ ), trabecular number (Tb.N), degree of Anisotropy (DA) and bone mineral density (BMD). c 3-Point bending test showing bending strength $(\mathrm{M})$, namely bending elasticity of long bones, decreased in null mice compared to wild type mice. d 3-Point bending test showing force at break (W), namely resistance of long bones to breakage. Data are presented as mean \pm SEM. $n=7-8$ mice per group. ${ }^{*} p \leq 0.05,{ }^{* *} p \leq 0.01$
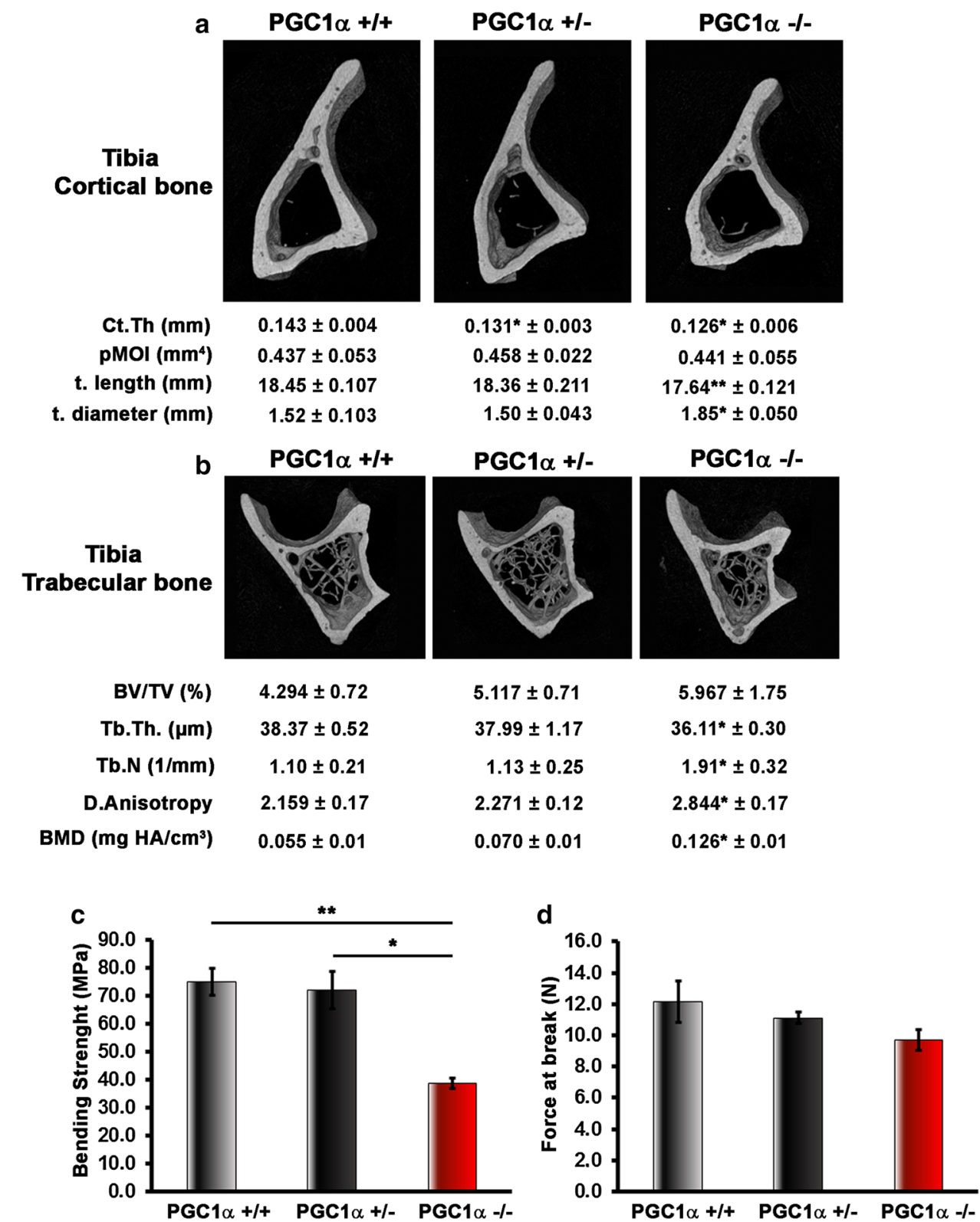
PGC1 $\alpha^{+/-}(-11.25 \%, p<0.05)$ and PGC1 $\alpha^{-/-}(-20.7 \%$, $p<0.05$ ) mice compared to wild type littermates (Fig. 2a). Furthermore, femurs from PGC1 $\alpha^{-/-}$mice showed decreased resistance to torsional forces, quantified as pMOI $(-20.88 \%$ vs PGC1 $\alpha^{+/+}, p<0.05$ ). Although it was observed the same trend seen in the tibia, trabecular bone in femurs from either knock out or heterozygous mice was unaffected, showing no significant variations respect to wild type mice, and also the bending strength and the force at break were unchanged (Fig. 2b, c). However, given that femur cortical thickness is reduced by $20 \%$, this is mostly reflected in a reduction of torsional strength, as demonstrated by the significant reduction in pMOI, rather than bending strength. In addition, by analyzing the trabecular bone of the spine, we found that knock out mice displayed the same defect observed in the tibia, namely decreased Tb.Th. $\left(-8.5 \%\right.$ vs PGC1 $\left.\alpha^{+/+}, p<0.05\right)$ and increased Tb.N $\left(+42 \%\right.$ vs PGC1 $\left.\alpha^{+/+}, p<0.05\right)$, despite unchanged BV/TV (Fig. 2d).

To determine whether the dramatic reduction in cortical thickness observed in $\mathrm{PGC} 1 \alpha^{-/-}$mice is associated with increased bone resorption or with a deficit in bone formation or both, we stained decalcified sections of tibiae to identify osteoclasts by TRAP (Fig. 3a) or to identify osteoblasts by ALP (Fig. 3b). As shown in Fig. 3a, osteoclast number (OCs Nr) per bone perimeter (BP) was 2.5 times higher in PGC1 $\alpha^{+/-}(p<0.05)$ and three times higher in PGC $1 \alpha^{-/-}$mice $(p<0.01)$ compared to wild type littermate. The same result was obtained by measuring the osteoclast surface area (OCs S) on bone surface area (BS) $(p<0.01)$. On the contrary, either the number of osteoblasts or their surface did not differ among genotypes (Fig. 3b). We sought to further characterize osteoclast activity in PGC $1 \alpha^{-/-}$mice in vivo, therefore, we assayed serum markers of collagen type 1 crosslinked C-telopeptide (CTX-I) which was significantly increased in PGC1 $\alpha^{-/-}$mice $(+42 \%, p<0.05)$ compared with WT littermates (Fig. 3c). Furthermore, in agreement with the unchanged osteoblast number, serum levels of procollagen type 1 amino terminal propeptide (P1NP) were not significantly different in PGC1 $\alpha^{-/-}$mice compared with WT mice (Fig. 3d). Furthermore, dynamic histomorphometry assessed by timed injections of xylenol orange and calcein in mice showed no significant difference in bone formation parameters between wild type and knock out mice (Fig. 3e).

Despite bone formation markers were unaffected, we found a lower positivity for osteocalcin $(\mathrm{Ocn})$, the most abundant non-collagenous protein of bone matrix, at the periostal surface of tibiae from $\mathrm{PGC} 1 \alpha^{-/-}$mice $(-70 \%$, $p<0.05$ ) compared with WT littermates (Fig. 3f).

Since cortical bone consists mainly of osteocytes, we investigated if there were any changes in their number and activity. As showed in Fig. 4a, osteocyte number (OYs Nr) per bone surface (BS) did not differ among genotypes, as well as sclerostin (Sost) (Fig. 4b) and Dickkopf-related protein 1 (Dkk1) (Fig. 4c) mRNAs expression. However, we found a significant increase in the number of TRAP positive osteocytes located close to the bone-resorbing surface, in both PGC $1 \alpha^{+/-}$and PGC1 $1 \alpha^{-/-}$mice compared to wild type littermate (Fig. 4d, e).

Given that PGC- $1 \alpha$ is a major regulator of mitochondrial biogenesis, we aimed to investigate whether it could also regulate in bone the transcription of nuclear genes encoding mitochondrial proteins, as well acknowledged in skeletal muscle [15]. We found that expression of the mitochondrial transcription factor A (Tfam) mRNA was significantly down-regulated in cortical bone of both $\mathrm{PGC} 1 \alpha^{+/-}$and PGC $1 \alpha^{-l-}$ mice (Fig. 5a). This reduction was paralleled by a decrease, albeit not significant, of osterix (Osx) mRNA expression (Fig. 5b). As already observed for protein levels (Fig. 3f), mRNA levels of $O c n$, were significantly decreased by 54 and $48 \%$ in PGC $1 \alpha^{+/-}$and PGC1 $1 \alpha^{-/-}$mice, respectively (Fig. 5c).

To investigate whether mesenchymal stem cell commitment was influenced by PGC $1 \alpha$ deletion, we analyzed bone marrow isolated from long bones in vivo. The expression of CCAAT/enhancer-binding protein alpha $(C / E B P \alpha)$, which is mainly involved in cell fate to drive toward adipocytes differentiation, was slightly increased in bone marrow from PGC1 $1 \alpha^{-/-}$(Fig. 5d). Peroxisome proliferator-activated receptor $\gamma$ (Ppary) mRNA was not changed either in PGC- $1 \alpha^{+/-}$or PGC- $1 \alpha^{-/-}$mice (Fig. 5e). Instead, a lower expression of collagen I (Coll I) mRNA was observed in bone marrow harvested from PGC1 $\alpha^{+/-}(-42 \%$ vs PGC $\left.1 \alpha^{+/+}, p<0.05\right)$ and from $\mathrm{PGC} 1 \alpha^{-/-}(-40 \%$ vs PGC1 $\left.\alpha^{+/+}, p<0.05\right)$, indicating decreased precursor differentiation toward an osteoblast lineage (Fig. 5f). Ex vivo cultures of whole bone marrow cells, showed that PGC1 $\alpha$ deficiency led to higher osteoclast formation than wild type mice (Fig. 5g), as already observed in vivo (Fig. 3a). Specifically, we observed an increase in the number of osteoclasts with more than 10 nuclei, whereas the number of smaller mature osteoclasts $(3<$ nuclei $<10)$ was unchanged. By analysing osteoblast differentiation in cultures of bone marrow stromal cells depleted from the non-adherent fraction, we found a significant reduction in the number of ALP positive cells and mineralized nodules in PGC1 $\alpha^{-/-}$mice with respect to wild type (Fig. 5h-i). Surprisingly, the same reduction was observed in the number of TRAP positive osteoclasts differentiated from PGC1 $\alpha^{-/-}$monocyte depleted from the adherent fraction of bone marrow stromal cells (Fig. 5j). Searching for an osteoblast-mediated indirect mechanism regulating osteoclast differentiation in vivo, we found that the receptor activator of NF-kB ligand (Rankl)/ osteoprotegerin $(\mathrm{Opg})$ ratio was strongly increased in bone marrow isolated from long bones of both heterozygous and knockout mice (Fig. 5k). The increased ratio was dependent 


\section{Femurs}

Cortical

Ct.Th (mm)

pMOI $\left(\mathrm{mm}^{4}\right)$

f. length $(\mathrm{mm})$

f. diameter ( $\mathrm{mm}$ )

Trabecular

BV/TV (\%)

Tb.Th. ( $\mu \mathrm{m})$

Tb.N (1/mm)

D.Anisotropy

BMD (mg HA/cm ${ }^{3}$ )

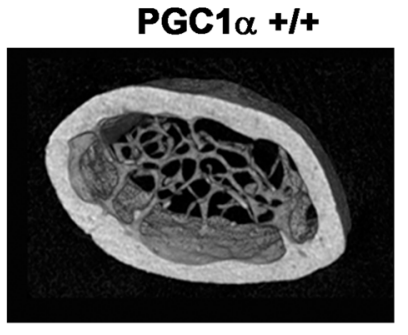

$0.169 \pm 0.003$

$0.412 \pm 0.02$

$15.11 \pm 0.13$

$2.12 \pm 0.01$

$4.208 \pm 0.84$

$42.49 \pm 2.69$

$1.12 \pm 0.11$

$1.515 \pm 0.08$

$0.048 \pm 0.01$
PGC1 $\alpha+/-$

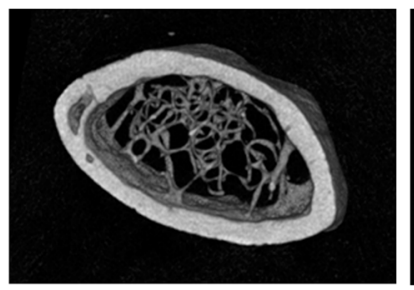

$0.150^{*} \pm 0.004$

$0.388 \pm 0.03$

$14.86 \pm 0.20$

$2.00 \pm 0.05$

$3.385 \pm 0.71$

$37.92 \pm 2.28$

$0.92 \pm 0.22$

$1.782 \pm 0.18$

$0.055 \pm 0.01$
PGC1 $\alpha$-/-

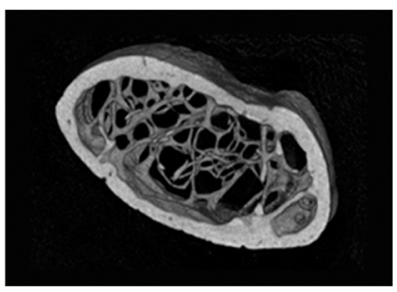

$0.134^{*} \pm 0.005$

$0.326^{*} \pm 0.02$

$15.11 \pm 0.48$

$1.92 \pm 0.10$

$5.304 \pm 0.85$

$36.14 \pm 2.67$

$1.53 \pm 0.13$

$2.01 \pm 0.22$

$0.098 \pm 0.01$

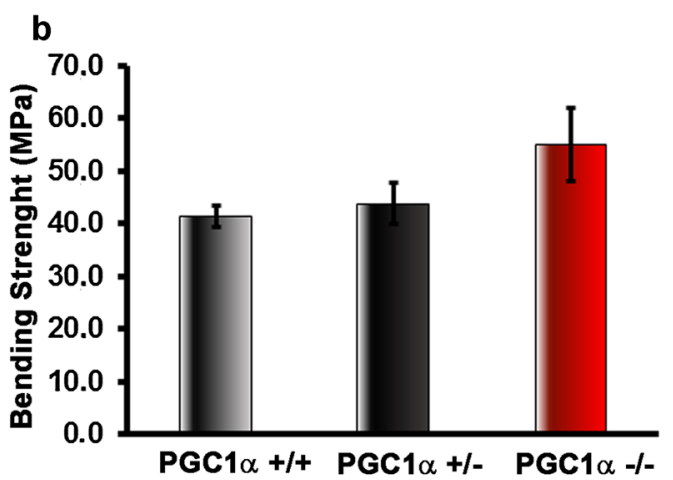

C

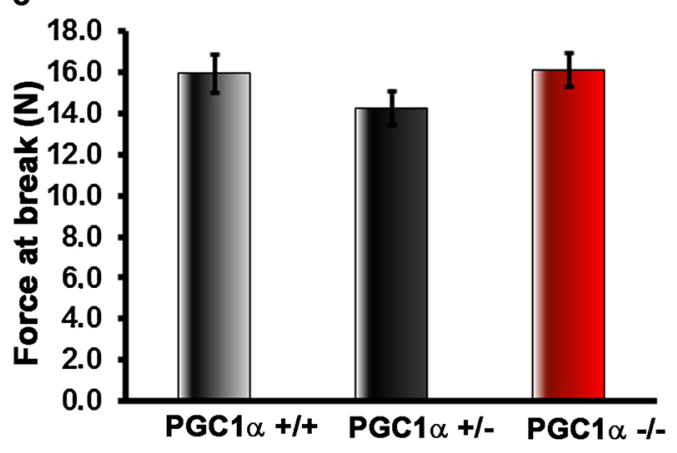

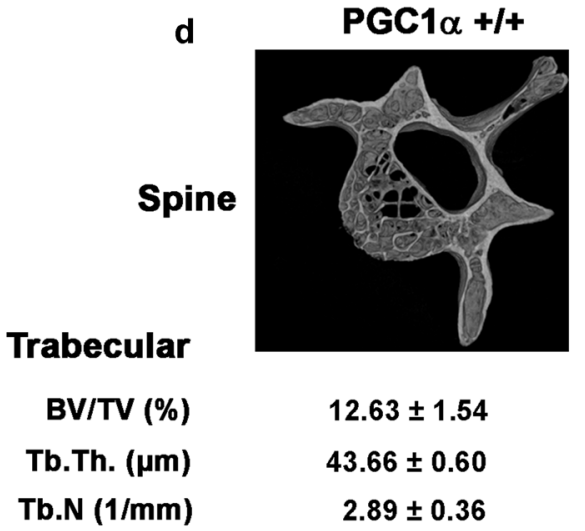

Fig. 2 Effect of PGC1 $\alpha$ whole body deletion on cortical and trabecular bone of femur and trabecular bone of spine. a Representative micro-CT-generated section images of cortical (midshaft) and trabecular (metaphyseal) bone in femur harvested from $\mathrm{PGC} 1 \alpha^{+/+}$, $\mathrm{PGC} 1 \alpha^{+/-}$and PGC $1 \alpha^{-/-}$mice. Cortical bone parameters included cortical thickness (Ct.Th), polar moment of inertia (pMOI), femur length (f. length) and diameter (f. diameter). Trabecular bone parameters included bone volume/total volume (BV/TV), trabecular thick-

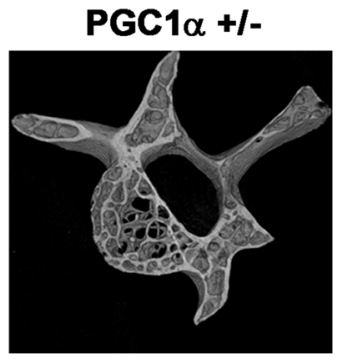

$14.23 \pm 1.32$
$44.41 \pm 2.48$
$3.21 \pm 0.28$

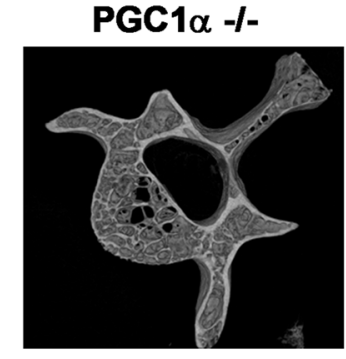

$16.46 \pm 0.42$

$40.01^{*} \pm 1.16$

$4.12^{*} \pm 0.09$

ness (Tb.Th), trabecular number (Tb.N), degree of Anisotropy (DA) and bone mineral density (BMD). b 3-Point bending test showing bending strength $(\mathrm{M})$, namely bending elasticity of long bones. c 3-Point bending test showing force at break (W), namely resistance of long bones to breakage. d Representative micro-CT-generated section images of L5 vertebra and calculated trabecular parameters (BV/TV, Tb.Th., Tb.N.). Data are presented as mean \pm SEM. $n=7-8$ mice per group. $* p \leq 0.05$ 


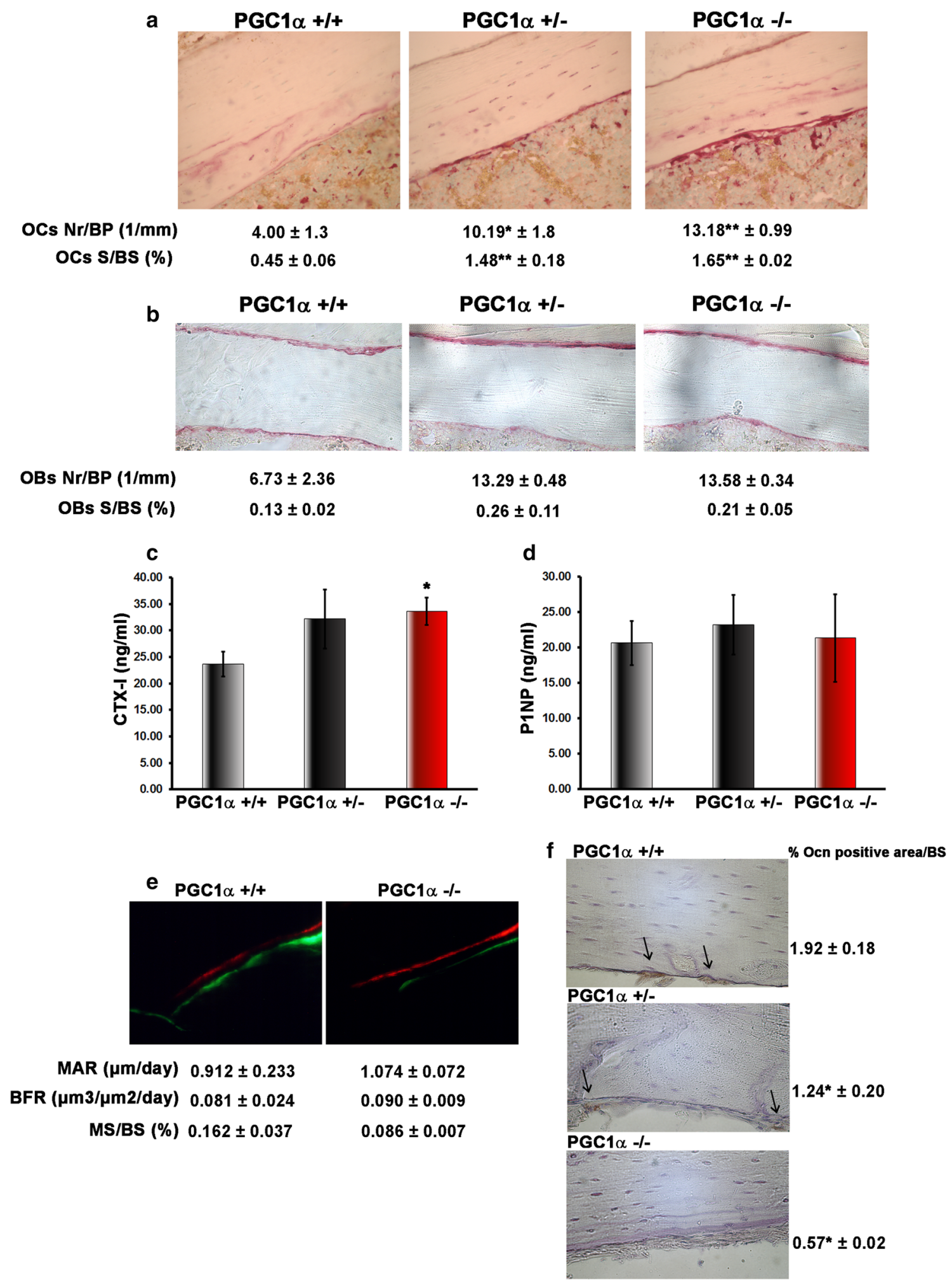

on raised levels of Rankl mRNA rather than Opg decline, whose expression was indeed unchanged among genotypes.

As previously showed by others [12], we found that PGC $1 \alpha^{-/-}$mice weigh approximately $30 \%$ less than wild type littermates $(p<0.01)$, as well as heterozygous mice $\left(-23 \%\right.$ vs PGC1 $\left.\alpha^{+/+}, p<0.01\right)$ (Fig. 6a). Of note, these mice displayed a lower ratio of inguinal WAT (iWAT)/ body weight (Fig. 6b). Expectedly, histological analysis of iWAT revealed profound $\sim 75 \%$ decrease in adipocyte area in both PGC $1 \alpha^{+/-}$and PGC $1 \alpha^{-/-}$mice $(p<0.001)$ (Fig. 6c). 
4Fig. 3 PGC1 $\alpha$ deficiency increases TRAP-positive osteoclast number and concentration of serum bone resorption marker CTX-I. a Representative images (magnification: $\times 40$ ) of TRAP-stained osteoclasts and $\mathbf{b}$ ALP-stained osteoblasts in tibial diaphyseal sections of PGC $1 \alpha^{+/+}, \mathrm{PGC} 1 \alpha^{+/-}$and PGC $1 \alpha^{-/-}$mice, together with cell counts (OCs and OBs, respectively) per bone perimeter (BP) and cell surface (S) per bone surface (BS). Concentrations of serum bone resorption marker CTX-I (c) and serum bone formation marker P1NP (d) were determined by ELISA. e Dynamic histomorphometry on tibial sections after timed injections (8 and 20 days before death) of xylenol orange and calcein, respectively. Representative images are shown for PGC1 $\alpha^{+/+}$and PGC1 $\alpha^{-/-}$mice, together with calculated indices of bone formation, including mineralized mineral apposition rate (MAR), bone formation rate (BFR), and mineralized surface/total bone surface $(\mathrm{MS} / \mathrm{BS})$, magnification $\times 20$. $\mathbf{f}$ Representative images of immunohistochemistry staining of Ocn protein on tibial sections (magnification: $\times 40$ ) and quantitative assessment of percentage of Ocn staining. Data are presented as mean \pm SEM. $n=5-6$ mice per group. $* p \leq 0.05, * * p \leq 0.01$
Although already evident from morphology, to exclude that adipocyte size was dependent from a "browning" activation, we measured the expression of uncoupling protein 1 $(U c p 1)$, master gene regulator of this trans-differentiation program wherein white adipocytes shift from a WAT to a brown adipose tissue (BAT)-like phenotype [16]. In both PGC $1 \alpha^{+/-}$and PGC1 $\alpha^{-/-}$mice, Ucpl mRNA was lower that wild type littermates (Fig. 6d). Moreover, in iWAT from PGC $1 \alpha^{+/-}$and PGC $1 \alpha^{-/-}$mice, we found a lower expression of adiponectin (AdipoQ) mRNA (Fig. 6e), whereas mRNA codifying for Leptin, the other major adipocyte-derived hormone, was fourfolds higher than wild type mice (Fig. 6f). Interestingly, by analysing bone marrow adipocytes in histological sections of long bones, we found a very similar phenotype observed in iWAT, namely $\sim 66 \%\left(\mathrm{PGC} 1 \alpha^{+/-}\right.$, $p<0.05)$ and $\sim 43 \%\left(\mathrm{PGC} 1 \alpha^{-1-}, p<0.01\right)$ decrease in
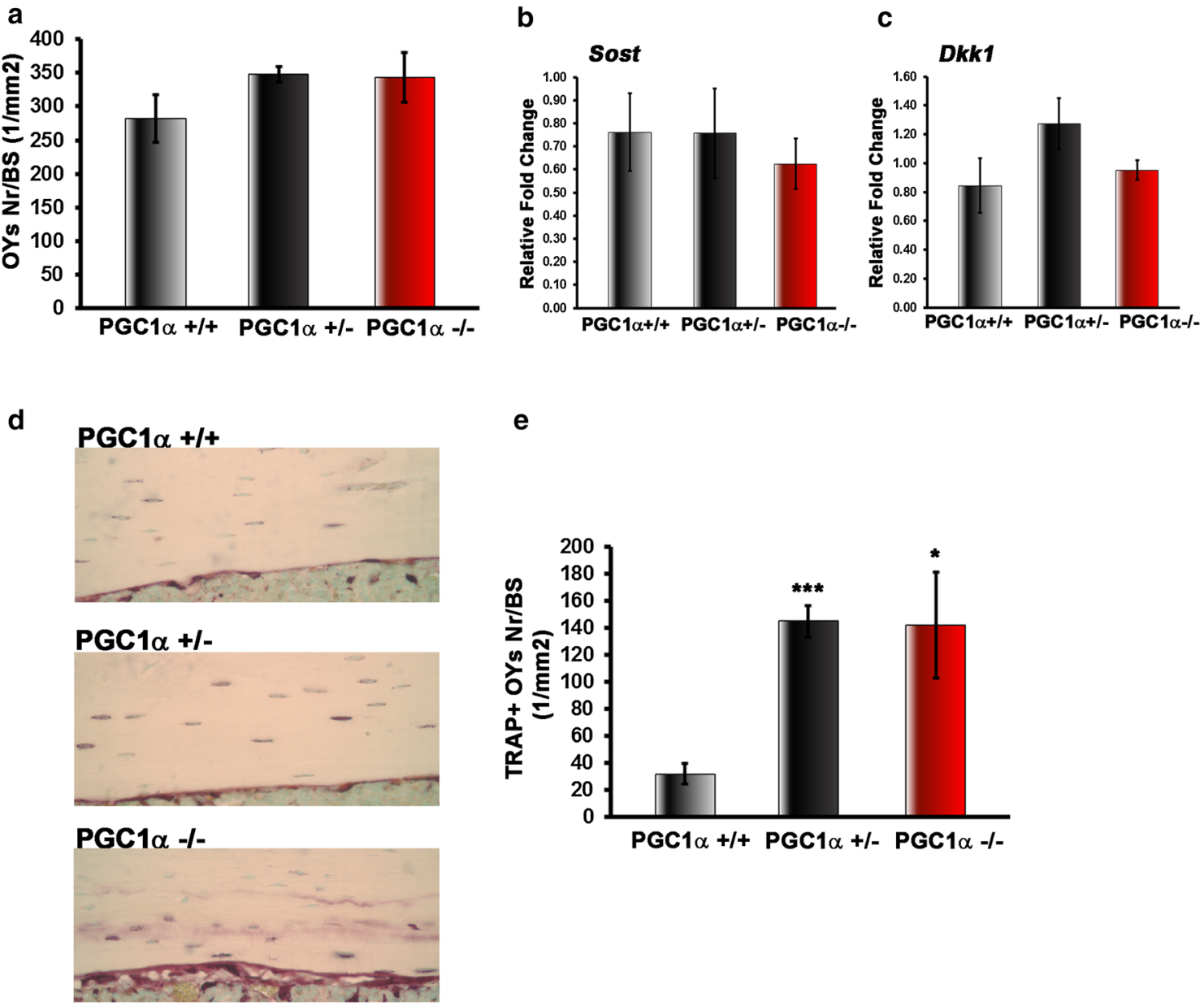

e

PGC1 $\alpha+/+$ PGC1 $\alpha+/-$ PGC1 $\alpha-/-$

Fig. 4 PGC1 $\alpha$ deletion increases number of TRAP positive osteocytes. a Osteocytes (OYs) count per bone surface (BS). b, c Gene expression of proteins secreted by osteocytes (Sost and Dkkl) were evaluated (qPCR) in bone (depleted of bone marrow) isolated from femurs and tibiae of PGC1 $1 \alpha^{+/+}, \mathrm{PGC} 1 \alpha^{+/-}$and PGC1 $1 \alpha^{-/-}$mice. d
TRAP-stained osteocytes in bone sections of PGC1 $\alpha^{+/+}$, PGC $1 \alpha^{+/-}$ and $\mathrm{PGC} 1 \alpha^{-/-}$mice, together with cell counts per bone surface (BS). Data are presented as mean \pm SEM. $n=5-6$ mice per group. $* p \leq 0.05, * * * p \leq 0.001$ 
Cortical Bone
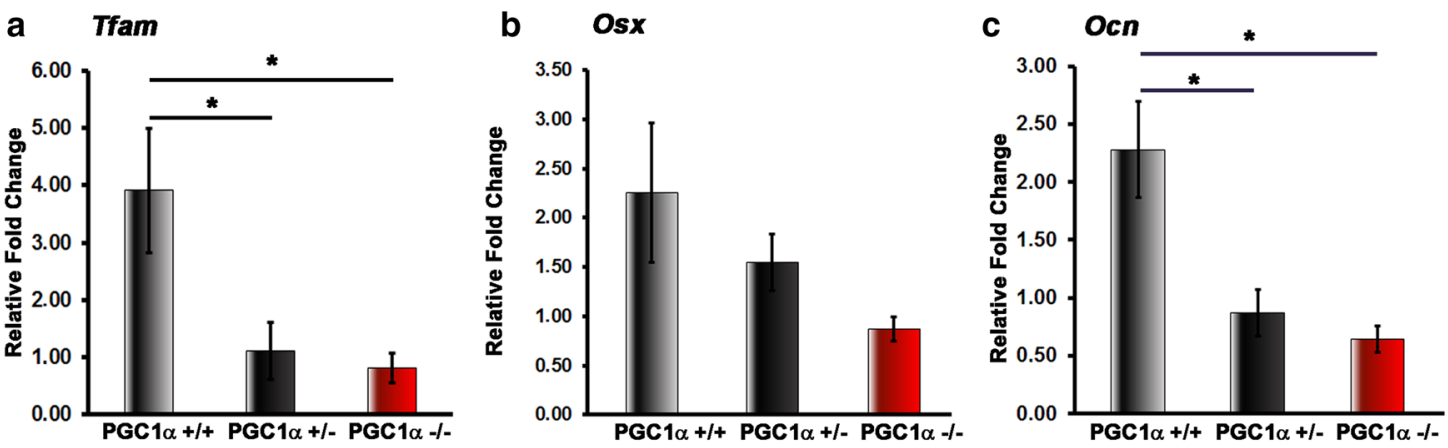

Bone Marrow
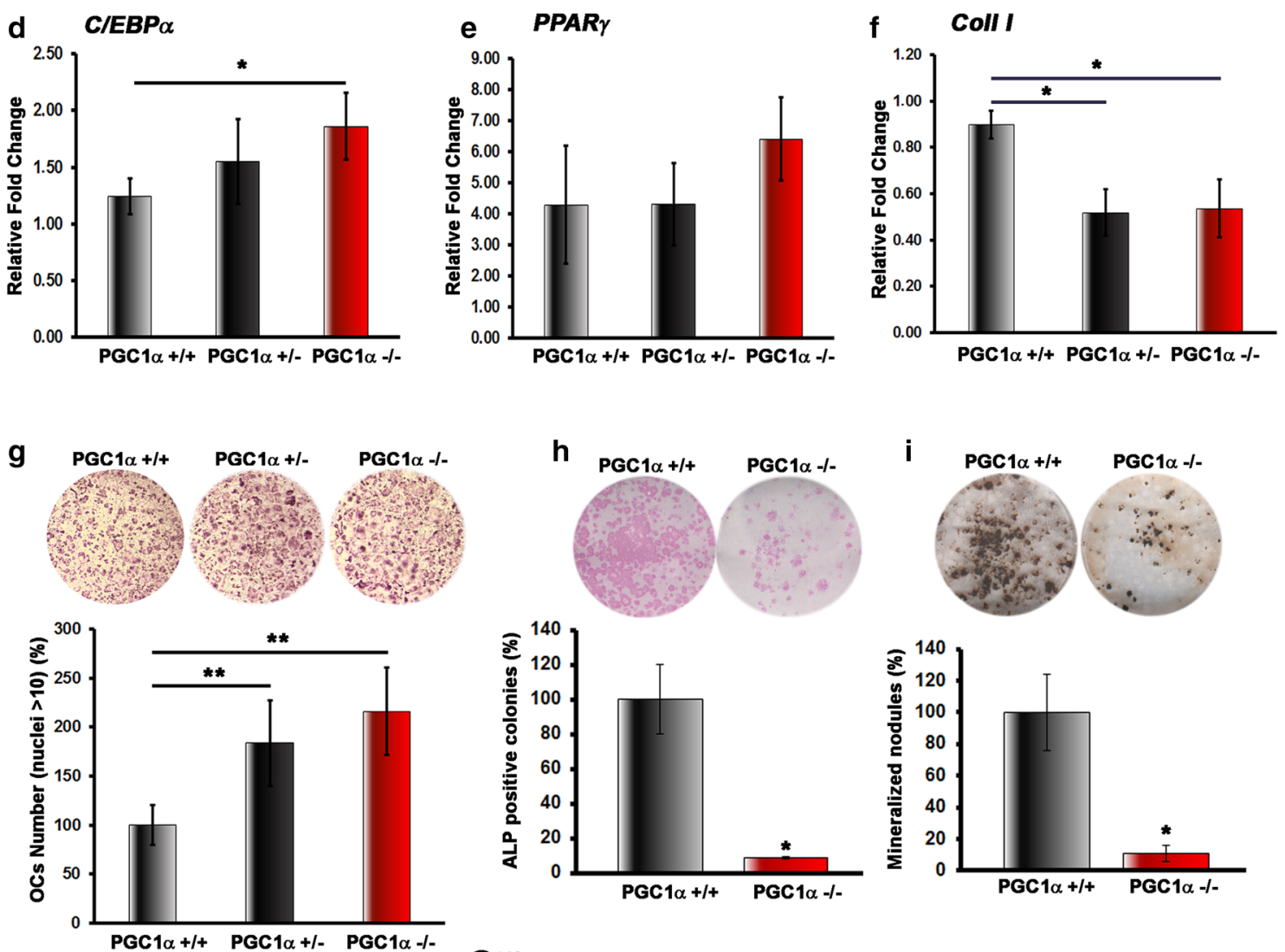

h PGC1 $\alpha+/+\quad$ PGC1 $\alpha-/-$
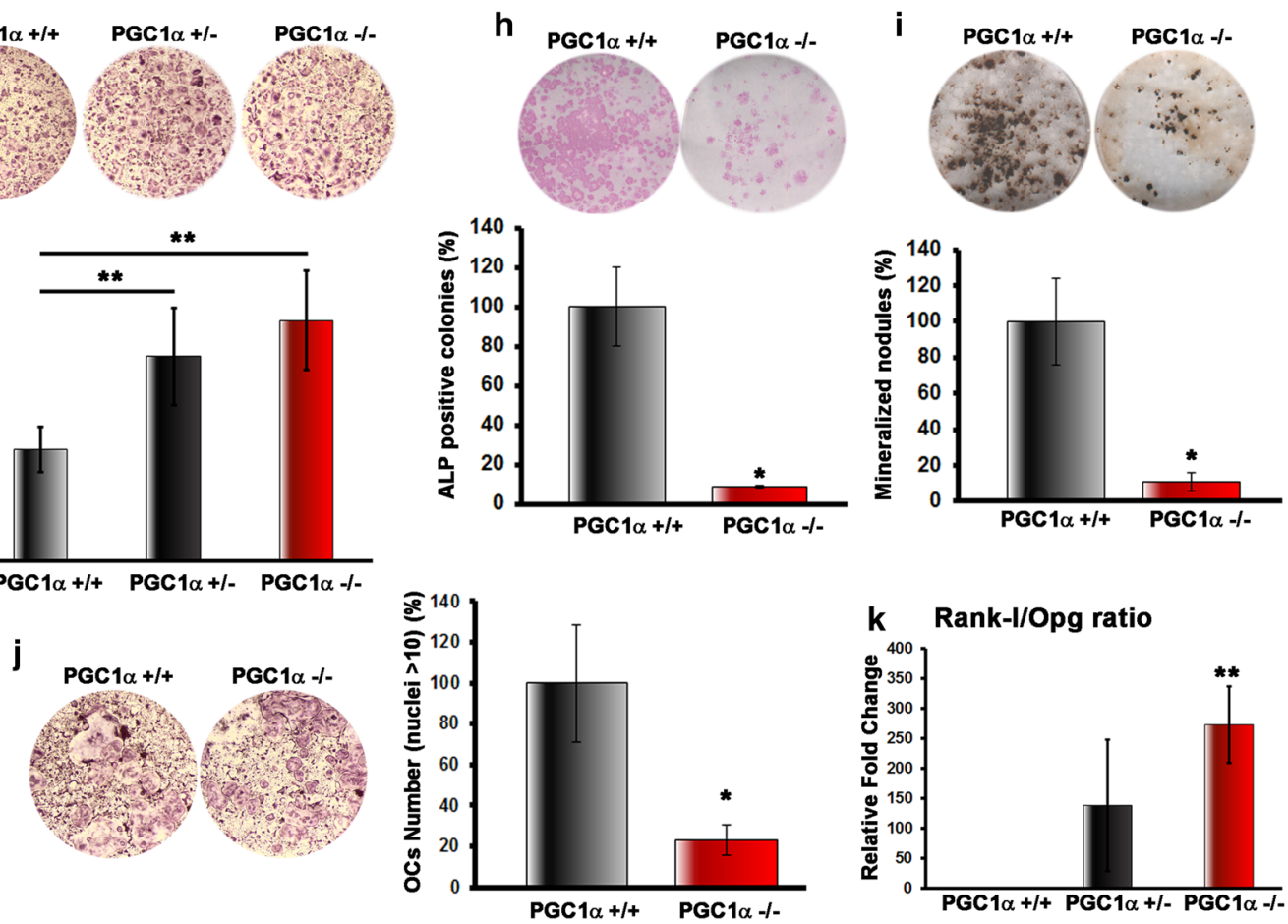

adipocyte area/bone marrow area, despite unchanged number (Fig. 6g, h).

\section{Discussion}

This work shows for the first time that PGC $1 \alpha$ deficiency negatively regulates bone mass and strength in aged mice. 
4Fig. 5 PGC1 $\alpha$ deletion affects mitochondrial and osteoblast marker gene expression in cortical bone and osteoblast/adipocyte lineage master genes in bone marrow. a Mitochondrial transcription factor A Tfam mRNA expression (qPCR) in bone (depleted of bone marrow) isolated from femurs and tibiae of PGC $1 \alpha^{+/+}, \mathrm{PGC} 1 \alpha^{+/-}$and PGC $1 \alpha^{-/-}$mice. b, c Osteoblast marker genes (Oxs and Ocn) were evaluated (qPCR) in bone (depleted of bone marrow) isolated from femurs and tibiae of PGC $1 \alpha^{+/+}, \mathrm{PGC} 1 \alpha^{+/-}$and PGC $1 \alpha^{-/-}$mice. d-f $C / E B P \alpha$, Ppar $\gamma$ and Coll1 mRNA expression (qPCR) in whole bone marrow isolated from femurs and tibiae of PGC $1 \alpha^{+/+}, \mathrm{PGC} 1 \alpha^{+/-}$and PGC $1 \alpha^{-/-}$mice. $g$ Whole bone marrow cells were grown in osteoclast differentiation medium. Representative wells and the percentage of TRAP-positive cells versus PGC1 $\alpha^{+/+}$are shown. h, i Representative wells of bone marrow stromal cells from $\mathrm{PGC} 1 \alpha^{+/+}$and PGC $1 \alpha^{-/-}$mice cultured in osteogenic medium $(50 \mu \mathrm{g} / \mathrm{mL}$ ascorbic acid and $10^{-2} \mathrm{M} \beta$-glycerophosphate). The percentage of ALP-positive colonies (10 days) (h) and von Kossa-positive mineralized nodules (21 days) (i) versus PGC1 $1 \alpha^{+/+}$are shown. j Representative wells of mature osteoclasts differentiated from bone marrow non-adherent fraction of $\mathrm{PGC} 1 \alpha^{+/+}$and $\mathrm{PGC} 1 \alpha^{-/-}$mice and cultured in osteoclast differentiation medium. The percentage of TRAP-positive cells (>10 nuclei) versus PGC1 $\alpha^{+/+}$are shown. $\mathbf{k}$ Rankl/Opg ratio was evaluated (qPCR) in bone marrow isolated from femurs and tibiae of PGC $1 \alpha^{+/+}, \mathrm{PGC} 1 \alpha^{+/-}$and PGC $1 \alpha^{-/-}$mice. Data are presented as mean \pm SEM. $n=5-6$ mice per group. $* p \leq 0.05$, $* * p \leq 0.01$

Our study arises from the new evidence showing that PGC $1 \alpha$, master regulator of mitochondrial biogenesis, is broadly involved in functions of several tissues, thus becoming a crucial factor on whole body metabolism [3, 17]. Among all functions, it is well acknowledged that PGC $1 \alpha$ expression is strongly up-regulated in skeletal muscle after exercise [18], thereby driving the expression of mitochondrial genes [19]. Since an existing intimate relationship between skeletal muscle and bone has been wellrecognized [20], particularly during physical activity [21, 22], we aimed to investigate whether PGC1 $\alpha$ also plays a role in bone metabolism. Here we report that PGC1 $\alpha$ deficiency profoundly impaired cortical bone mass and strength in long bones, primarily at the tibia, in 12-months-old mice. PGC $1 \alpha$ deficiency led to reduction in cortical thickness and trabecular thickness (Tb.Th), whereas trabecular number (Tb.N) was higher than wild type mice, thus resulting in increased degree of anisotropy (DA). The micro-architectural anisotropy parameter measures the degree of directional organization of a material and, regarding bone, it is of particular interest for the mechanical-architecture relations [23]. Several reports in humans showed higher values of DA parameter in vertebral fracture cases [24] and the progressive preferential loss of oriented trabeculae, leading to higher degree of anisotropy, has been observed in long bones of osteoporotic patients $[25,26]$. In our hand, this alteration of the trabecular micro-architecture, accompanied by reduction of cortical thickness, suggested a possible impairment of mechanical properties of the tibia, which was indeed confirmed by $\sim 48.4 \%$ decrease of bending strength, thus implying that PGC1 $\alpha$ deficiency could lead to increased risk of fracture, despite the increase of BMD in trabecular bone.

The bone defect observed in PGC $1 \alpha^{-/-}$mice appears mainly dependent on increased osteoclast formation and activity. However, the number of osteoblasts, stained for ALP, was double in PGC $1 \alpha$ deficient mice with respect to wild type littermates. Albeit not significant, this result could partially explain why the number of trabeculae and BMD are increased in knock out mice.

Furthermore, despite unchanged levels of the bone formation marker P1NP, there seems to be a contribution of PGC1 $\alpha$ the osteoblast function, considering that its deletion results in a dramatic reduction of $O c n$ expression in cortical bone. Importantly, previous in vitro study reported that PGC1 $\alpha$ directly synergizes with Nurr1 to induce Ocn expression in osteoblasts [13], thus supporting our in vivo data showing a dramatic reduction of Ocn mRNA in long bone from PGC1 $\alpha$ deficient mice.

The Estrogen-related receptor alpha $(\mathrm{ERR} \alpha)$, first identified orphan nuclear receptor, was primarily thought to synergize with PGC $1 \alpha$ to solely regulate the transcription of genes involved in the oxidative phosphorylation and mitochondrial pathways [27]. However, it has been recently shown that three $\operatorname{ERR} \alpha$ response elements (ERR response element, ERRE) are present in the osteocalcin promoter, and ERR $\alpha$ interacts with $\mathrm{PGC} 1 \alpha$ to improve the osteocalcin promoter activity [28].

Consistent with the impaired synthesis of this bone-key protein [29], we investigated whether early genes involved in osteoblast differentiation were also affected by PGC $1 \alpha$ deletion. Therefore, we analyzed the expression of marker genes in bone marrow precursors demonstrating that mRNA for Coll I, the most abundant bone protein [29], was downregulated in PGC1 $\alpha$ mutant mice. Although the bone phenotype observed in vivo does not seem attributable to an osteoblast defect, given there were no variations in the MAR or in the serum level of P1NP, ex vivo differentiation assay showed that osteoblasts from PGC $1 \alpha^{-1-}$ mice have a cell autonomous defect characterized by delays of differentiation and activity. Surprisingly, also PGC1 $\alpha^{-/-}$osteoclasts, differentiated from monocyte cultures depleted from bone marrow stromal cells, showed the same delay in the differentiation process. This result was in contrast with those observed in vivo, as the increased number and surface of osteoclasts on cortical bone, as well as the elevated levels of the serum marker CTX-I. In addition, when osteoclasts were differentiated starting from a culture of non-pure monocytes, i.e. from the whole bone marrow, cells derived from mutated mice showed increased formation of multinucleated osteoclast. Although speculative, this suggested that it may exist an osteoblast-mediated indirect mechanism which leads to high formation and activity of osteoclasts in vivo, resulting in cortical thickness reduction in long bones of mutant mice. 

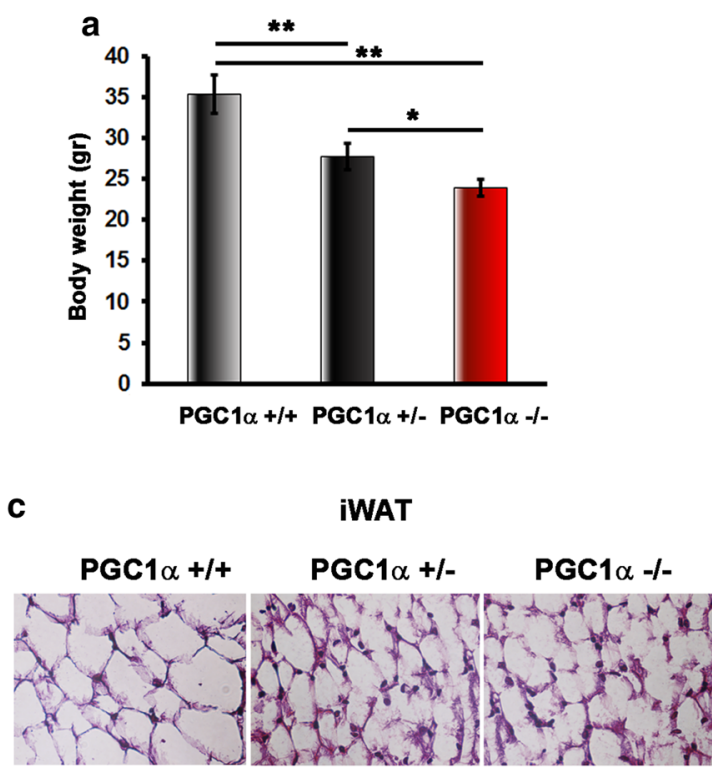
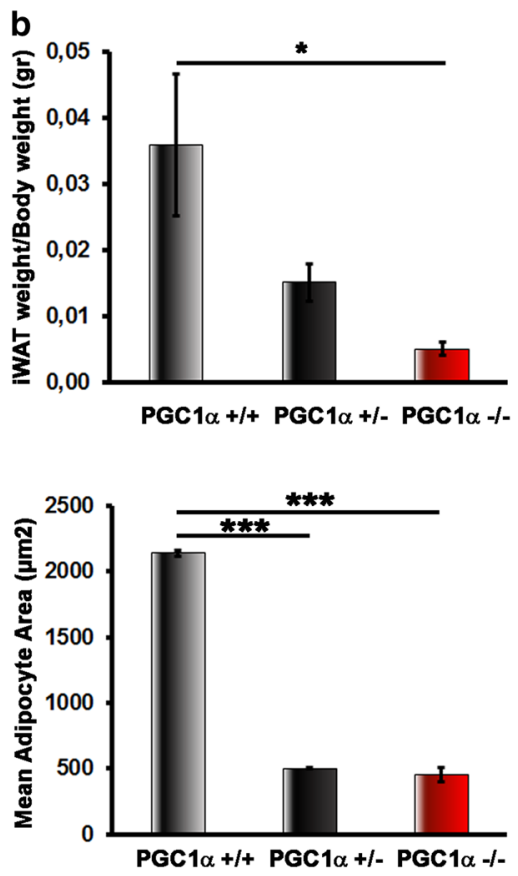

IWAT
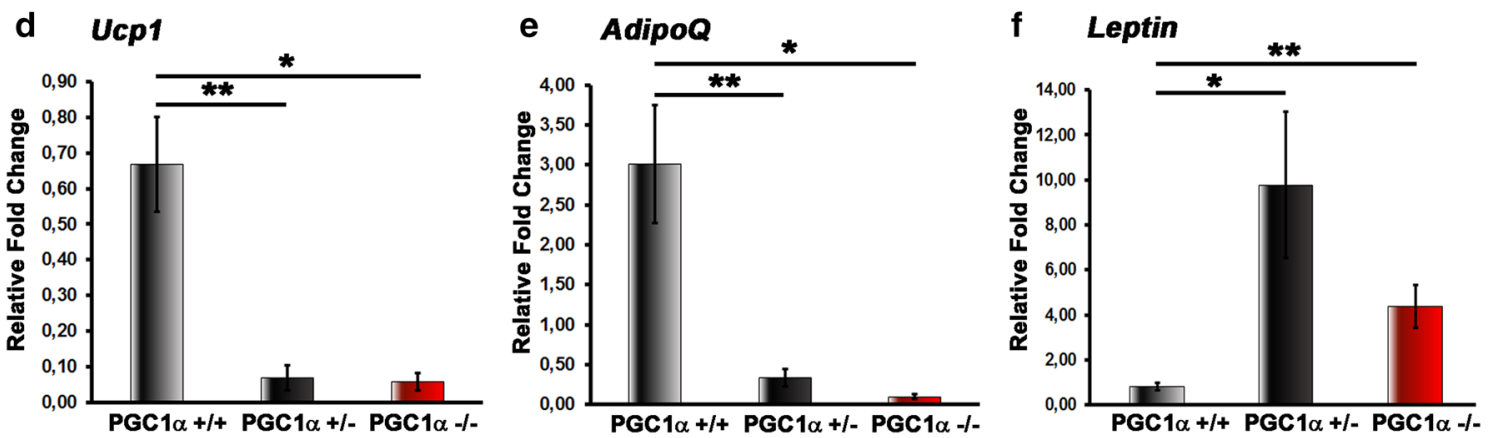

Bone Marrow
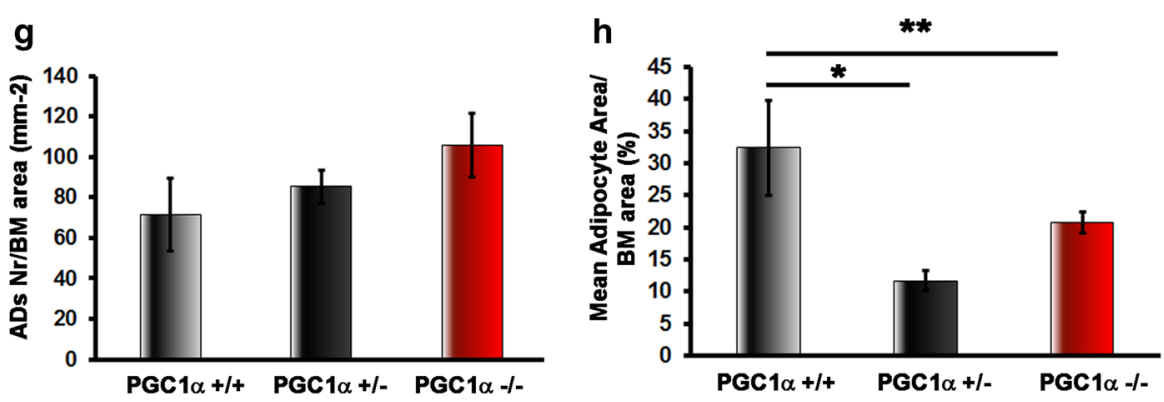

Fig. 6 PGC1 $\alpha$ deletion affects body weight, iWAT distribution and morphology along with expression of genes involved in the browning response and hormonal secretion. a Measured body weight. b iWAT weight normalized to total body weight from PGC1 $\alpha^{+/+}, \mathrm{PGC} 1 \alpha^{+/-}$ and PGC1 $1 \alpha^{-/-}$mice. c Photomicrographs of hematoxylin and eosin stained sections of iWAT from PGC $1 \alpha^{+/+}, \mathrm{PGC} 1 \alpha^{+/-}$and $\mathrm{PGC} 1 \alpha^{-/-}$ mice (magnification: $\times 40$ ) showing a significant decrease of mean adipocyte area in mutant mice compared to wild type. d-f Ucpl, Adipo $Q$ and Leptin mRNA expression (qPCR) in iWAT harvested from PGC1 $\alpha^{+/+}, \mathrm{PGC} 1 \alpha^{+/-}$and PGC1 $\alpha^{-/-}$mice. $\mathbf{g}$, h Adipocytes (ADs) number and area count per bone marrow area (BM area). Data are presented as mean \pm SEM. $n=5-6$ mice per group. ${ }^{*} p \leq 0.05$, $* * p \leq 0.01, * * * p \leq 0.001$ 
Searching for an osteoblast-mediated indirect mechanism stimulating osteoclast differentiation in vivo, we found that Rankl/Opg ratio was strongly increased, due to elevated levels of Rankl in the bone marrow of knock out mice.

Moreover, it is well known that adipocytes and osteoblasts originate from a common mesenchymal precursor within bone marrow and while mesenchymal stem cells activate their differentiation process toward adipo- or osteogenic cell fate, specific transcription factors become up-regulated [30]. Although PPAR $\gamma$ expression was unchanged, we found increased levels of $C / E B P \alpha$ mRNA in PGC1 $\alpha$ knock out mice. Further studies are required to understand if PGC1 $\alpha$ deletion leads to increased marrow adiposity which may contribute to the detrimental effect on bone health [31-33].

In addition to the decrease of body weight, we also observed that both $\mathrm{PGC} 1 \alpha^{+/-}$and $\mathrm{PGC} 1 \alpha^{-/-}$mice had lower ratio of iWAT/body weight, consistent with decreased adipocyte size. Recent evidence has shown that certain WAT depots have a higher propensity to form inducible brown fat [34], such as the inguinal WAT, whereas epididymal WAT is less prone to browning [34]. PGC $1 \alpha$ has been extensively studied in the classical brown fat (intrascapular), where it coactivates PPAR $\gamma$ to up-regulate $U c p l$ and consequently activates the thermogenesis [3]. To our knowledge, here we show for the first time that the lack of PGC1 $\alpha$ negatively regulated $U c p l$ expression also in inguinal WAT.

Several evidences claimed the existence of a reciprocal regulation between bone and energy metabolism [35, 36]. The hormone osteocalcin, in addition to its primary role as bone-building protein, also regulates energy metabolism, either by promoting insulin secretion by pancreatic $\beta$-cells or signaling in adipocytes where it induces the synthesis of adiponectin, the fat-specific hormone, and increases insulin sensitivity [37]. On the other hand, leptin, another adipocyte-derived hormone, inhibits bone mass accrual via sympathetic nervous system [38] and this action is partially counteracted by adiponectin [39]. Our data showed that these two hormones are influenced by PGC1 $\alpha$ deficiency in an opposite manner. Further studies could demonstrate if the lower expression of Adipo $Q$ and, at the same time, the higher expression of Leptin, may contribute to the impairment of bone mass observed in PGC1 $\alpha$ knock out mice. One limitation of our study is that, although the whole-body deletion of PGC1 $\alpha$ gives rise to viable off-spring [12], the characterization of their bone phenotype could have been masked by other systemic effects [40]. Therefore, the generation of PGC1 $\alpha$ conditional knockout models, with specific deletion in osteoblasts or osteoclasts, could provide in future a better understanding into the contribution of this transcription factor to bone metabolism. In addition to unexplored secondary systemic effects, the bone mass of PGC1 $\alpha$ knock out mice may have been affected by the $30 \%$ reduction of body weight respect to wild type littermates, thus resulting in a lower "load" on the skeleton. However, despite the high body mass has traditionally been considered positive to bone for the beneficial effect of mechanical loading on bone formation, several studies have achieved a clear consensus, suggesting instead that high fat mass could rather be detrimental to bone [41]. In parallel, several reports have ascertained that low body weight, as observed in animal and human models of caloric restriction and anorexia nervosa, often correlates with low bone mass and reduced BMD $[32,33]$. Furthermore, we found that differentiation of osteoblasts and osteoclasts is affected in mutant mice, providing evidence for a cell-autonomous role of PGC1 $\alpha$ in bone cells. Although future studies will be needed to better define if there are coupling factors, other than Rankl, which exacerbate osteoclast activity in vivo, overall results presented herein highlight for the first time that $\mathrm{PGC} 1 \alpha$ has a critical role in the regulation of bone mass.

Acknowledgements We thank Dr. Antonio Moschetta (Department of Interdisciplinary Medicine, "Aldo Moro" University of Bari, 70124 Bari, Italy) for the generous gift of $\mathrm{PGC} 1 \alpha$ heterozygous mice to generate the colony. This work was supported in part by MIUR Grant ex60\% (to M.G.), by SIOMMMS Grant (to G.C.) and by ERISTO (ESA) Grant (to M.G.)

Author Contribution GC, LL, UT, SC, MG designed research; LL, LS, MC, NC performed research; GC, LL, GB, GP, JR, ES, MFF, UT, SC, MG analyzed, interpreted and discussed the data; and GC, LL, MG wrote the paper.

\section{Compliance with Ethical Standards}

Conflict of interest Graziana Colaianni, Luciana Lippo, Lorenzo Sanesi, Giacomina Brunetti, Monica Celi, Nunzio Cirulli, Giovanni Passeri, Janne Reseland, Ernestina Schipani, Maria Felicia Faienza, Umberto Tarantino, Silvia Colucci, and Maria Grano declare that there is no conflict of interest regarding the publication of this paper.

Human and Animal Rights and Informed Consent This study is in accordance with the European Law Implementation of Directive 2010/63/EU and all experimental protocols were reviewed and approved by the Veterinary Department of the Italian Ministry of Health (Project 522-2016PR). Experimental procedures have been carried out following the standard biosecurity and the institutional safety procedures. For this type of study formal consent is not required.

\section{References}

1. Lin J, Wu H, Tarr PT, Zhang CY, Wu Z, Boss O, Michael LF, Puigserver P, Isotani E, Olson EN, Lowell BB, Bassel-Duby R, Spiegelman BM (2002) Transcriptional co-activator PGC- $1 \alpha$ drives the formation of slow-twitch muscle fibres. Nature 418(6899):797-801

2. Michael LF, Wu Z, Cheatham RB, Puigserver P, Adelmant G, Lehman JJ, Kelly DP, Spiegelman BM (2001) Restoration of insulin-sensitive glucose transporter (GLUT4) gene expression 
in muscle cells by the transcriptional coactivator PGC-1. Proc Natl Acad Sci USA 98(7):3820-3825

3. Puigserver P, Wu Z, Park CW, Graves R, Wright M, Spiegelman BM (1998) A cold-inducible coactivator of nuclear receptors linked to adaptive thermogenesis. Cell 92(6):829-839

4. Wu Z, Puigserver P, Andersson U, Zhang C, Adelmant G, Mootha V, Troy A, Cinti S, Lowell B, Scarpulla RC, Spiegelman BM (1999) Mechanisms controlling mitochondrial biogenesis and respiration through the thermogenic coactivator PGC-1. Cell 98(1):115-124

5. Lin J, Tarr PT, Yang R, Rhee J, Puigserver P, Newgard CB, Spiegelman BM (2003) PGC- $1 \beta$ in the regulation of hepatic glucose and energy metabolism. J Biol Chem 278(33):30843-30848

6. Irrcher I, Adhihetty PJ, Sheehan T, Joseph AM, Hood DA (2003) PPAR $\gamma$ coactivator- $1 \alpha$ expression during thyroid hormone- and contractile activity-induced mitochondrial adaptations. Am J Physiol 284(6):C1669-C1677

7. Ljubicic V, Joseph AM, Saleem A, Uguccioni G, Collu-Marchese M, Lai RY, Nguyen LM, Hood DA (2010) Transcriptional and post-transcriptional regulation of mitochondrial biogenesis in skeletal muscle: effects of exercise and aging. Biochem Biophys Acta 1800(3):223-234

8. Pilegaard H, Saltin B, Neufer PD (2003) Exercise induces transient transcriptional activation of the PGC- $1 \alpha$ gene in human skeletal muscle. J Physiol 546(3):851-858

9. Baar K, Wende AR, Jones TE, Marison M, Nolte LA, Chen M, Kelly DP, Holloszy JO (2002) Adaptations of skeletal muscle to exercise: rapid increase in the transcriptional coactivator PGC-1. Fed Am Soc Exp Biol 16(14):1879-1886

10. Goto M, Terada S, Kato M, Katoh M, Yokozeki T, Tabata I, Shimokawa T (2000) cDNA Cloning and mRNA analysis of PGC-1 in epitrochlearis muscle in swimming-exercised rats. Biochem Biophys Res Commun 274(2):350-354

11. Yoon JC, Puigserver P, Chen G, Donovan J, Wu Z, Rhee J, Adelmant G, Stafford J, Kahn CR, Granner DK, Newgard CB, Spiegelman BM (2001) Control of hepatic gluconeogenesis through the transcriptional coactivator PGC-1. Nature 413(6852):131-138

12. Lin J, Wu PH, Tarr PT, Lindenberg KS, St-Pierre J, Zhang CY, Mootha VK, Jäger S, Vianna CR, Reznick RM, Cui L, Manieri M, Donovan MX, Wu Z, Cooper MP, Fan MC, Rohas LM, Zavacki AM, Cinti S, Shulman GI, Lowell BB, Krainc D, Spiegelman BM (2004) Defects in adaptive energy metabolism with CNS-linked hyperactivity in PGC-1alpha null mice. Cell 119(1):121-135

13. Nervina JM, Magyar CE, Pirih FQ, Tetradis S (2006) PGC-1alpha is induced by parathyroid hormone and coactivates Nurr1-mediated promoter activity in osteoblasts. Bone 39(5):1018-1025

14. D'Errico I, Salvatore L, Murzilli S, Lo Sasso G, Latorre D, Martelli N, Egorova AV, Polishuck R, Madeyski-Bengtson K, Lelliott C, Vidal-Puig AJ, Seibel P, Villani G, Moschetta A (2011) Peroxisome proliferator-activated receptor-gamma coactivator 1-alpha (PGC1alpha) is a metabolic regulator of intestinal epithelial cell fate. Proc Natl Acad Sci USA 108(16):6603-6608

15. Uguccioni G, Hood DA (2011) The importance of PGC- $1 \alpha$ in contractile activity-induced mitochondrial adaptations. Am J Physiol Endocrinol Metab 300(2):E361-E371

16. Boström P, Wu J, Jedrychowski MP, Korde A, Ye L, Lo JC, Rasbach KA, Boström EA, Choi JH, Long JZ, Kajimura S, Zingaretti MC, Vind BF, Tu H, Cinti S, Højlund K, Gygi SP, Spiegelman BM (2012) A PGC1- $\alpha$-dependent myokine that drives brown-fat-like development of white fat and thermogenesis. Nature 481(7382):463-468

17. Puigserver P, Spiegelman BM (2003) Peroxisome proliferatoractivated receptor-gamma coactivator 1 alpha (PGC-1 alpha): transcriptional coactivator and metabolic regulator. Endocr Soc 24:78-90

18. Handschin C, Rhee J, Lin J, Tarr PT, Spiegelman BM (2003) An autoregulatory loop controls peroxisome proliferator-activated receptor gamma coactivator 1alpha expression in muscle. Proc Natl Acad Sci USA 100:7111-7116

19. Handschin C, Spiegelman BM (2011) PGC-1 coactivators and the regulation of skeletal muscle fiber-type determination. [Comment Lett] Cell Metab 13(4):351 (author reply 352).

20. Brotto M, Johnson ML (2014) Endocrine crosstalk between muscle and bone. Curr Osteoporo Rep 12(2):135-141

21. Colaianni G, Cuscito C, Mongelli T, Pignataro P, Buccoliero C, Liu P, Lu P, Sartini L, Di Comite M, Mori G, Di Benedetto A, Brunetti G, Yuen T, Sun L, Reseland JE, Colucci S, New MI, Zaidi M, Cinti S, Grano M (2015) The myokine irisin increases cortical bone mass. Proc Natl Acad Sci USA 112(39):12157-12162

22. Mera P, Laue K, Ferron M, Confavreux C, Wei J, Galán-Díez M, Lacampagne A, Mitchell SJ, Mattison JA, Chen Y, Bacchetta J, Szulc P, Kitsis RN, de Cabo R, Friedman RA, Torsitano C, McGraw TE, Puchowicz M, Kurland I, Karsenty G (2016) Osteocalcin signaling in myofibers is necessary and sufficient for optimum adaptation to exercise. Cell Metab 23(6):1078-1092

23. Kersh ME, Zysset PK, Pahr DH, Wolfram U, Larsson D, Pandy MG (2013) Measurement of structural anisotropy in femoral trabecular bone using clinical-resolution CT images. J Biomech 46(15):2659-2666

24. Chappard C, Brunet-Imbault B, Lemineur G, Giraudeau B, Basillais A, Harba R, Benhamou CL (2005) Anisotropy changes in post-menopausal osteoporosis: characterization by a new index applied to trabecular bone radiographic images. Osteoporos Int 16(10):1193-1202

25. Singh M, Nagrath AR, Maini PS (1970) Changes in trabecular pattern of the upper end of the femur as an index of osteoporosis. J Bone Joint Surg Am 52(3):457-467

26. Newitt DC, van Rietbergen B, Majumdar S (2002) Processing and analysis of in vivo high-resolution MR images of trabecular bone for longitudinal studies: reproducibility of structural measures and micro-finite element analysis derived mechanical properties. Osteoporos Int 13(4):278-287

27. Zhang Y, Ma K, Sadana P, Chowdhury F, Gaillard S, Wang F, McDonnell DP, Unterman TG, Elam MB, Park EA (2006) Estrogen-related receptors stimulate pyruvate dehydrogenase kinase isoform 4 gene expression. J Biol Chem 281:39897-39906

28. Wang H, Wang J (2013) Estrogen-related receptor alpha interacts cooperatively with peroxisome proliferator-activated receptorgamma coactivator-1alpha to regulate osteocalcin gene expression. Cell Biol Int 37(11):1259-1265

29. Florencio-Silva R, Rodrigues da Silva Sasso G, Sasso-Cerri E, Simões MJ, Cerri PS (2015) Biology of bone tissue: structure, function, and factors that influence bone cells. BioMed Res Int. https://doi.org/10.1155/2015/421746

30. Colaianni G, Brunetti G, Faienza MF, Colucci S, Grano M (2014) Osteoporosis and obesity: role of Wnt pathway in human and murine models. World J Orthop 5(3):242-246

31. Fazeli PK, Horowitz MC, MacDougald OA, Scheller EL, Rodeheffer MS, Rosen CJ, Klibanski A (2013) Marrow fat and bonenew perspectives. J Clin Endocrinol Metab 98(3):935-945

32. Devlin MJ, Cloutier AM, Thomas NA, Panus DA, Lotinun S, Pinz I, Baron R, Rosen CJ, Bouxsein ML (2010) Caloric restriction leads to high marrow adiposity and low bone mass in growing mice. J Bone Miner Res 25:2078-2088

33. Bredella MA, Fazeli PK, Miller KK, Fazeli PK, Miller KK, Misra M, Torriani M, Thomas BJ, Ghomi RH, Rosen CJ, Klibanski A 
(2009) Increased bone marrow fat in anorexia nervosa. J Clin Endocrinol Metab 94(6):2129-2136

34. Waldén TB, Hansen IR, Timmons JA, Cannon B, Nedergaard J (2012) Recruited vs. nonrecruited molecular signatures of brown, "brite," and white adipose tissues. Am J Physiol Endocrinol Metab 302(1):E19-E31

35. Karsenty G, Oury F (2012) Biology without walls: the novel endocrinology of bone. Annu Rev Physiol 74:87-105

36. Isaia GC, D'Amelio P, Di Bella S, Tamone C (2005) Is leptin the link between fat and bone mass? J Endocrinol Investig $28(10$ Suppl):61-65

37. Lee NK, Sowa H, Hinoi E, Ferron M, Ahn JD, Confavreux C, Dacquin R, Mee PJ, McKee MD, Jung DY, Zhang Z, Kim JK, Mauvais-Jarvis F, Ducy P, Karsenty G (2007) Endocrine regulation of energy metabolism by the skeleton. Cell 130(3):456-469
38. Takeda S, Elefteriou F, Levasseur R, Liu X, Zhao L, Parker KL, Armstrong D, Ducy P, Karsenty G (2002) Leptin regulates bone formation via the sympathetic nervous system. Cell 111(3):305-317

39. Kajimura D, Lee HW, Riley KJ, Arteaga-Solis E, Ferron M, Zhou B, Clarke CJ, Hannun YA, DePinho RA, Guo XE, Mann JJ, Karsenty G (2013) Adiponectin regulates bone mass via opposite central and peripheral mechanisms through FoxO1. Cell Metab 17(6):901-915

40. Rowe GC, Arany Z (2014) Genetic models of PGC-1 and glucose metabolism and homeostasis. Rev Endocr Metab Disord 15(1):21-29

41. Rosen CJ, Bouxsein ML (2006) Mechanisms of disease: is osteoporosis the obesity of bone? Nat Clin Pract Rheumatol 2:35-43 